\title{
Inner space: translating advances in human medicine to minimise the invasiveness of marine tagging procedures
}

\author{
Ela Patel ${ }^{1}$, James Lea ${ }^{2,3^{*}}$ (i) and Christopher Clarke $^{3}$
}

\begin{abstract}
Background: Surgical implantation of transmitters and data loggers into wild fish is commonplace among studies of their behaviour and ecology. Nonetheless, concerns remain regarding the procedures required for implantation of internal tags, and there is a subsequent responsibility by researchers to minimise the invasiveness of any tagging protocol. To this end, we investigated whether advances in human laparoscopic surgery could be used to make tag implantation less invasive and more efficient.
\end{abstract}

Results: Use of a trocar meant that incisions could be $<50 \%$ in length, muscle was parted instead of cut, and no sharp edges entered the abdominal cavity. A barbed suture then meant the incision could be closed more easily without the need to tie any knots.

Conclusions: Combined use of a trocar and barbed suture made the surgical implantation procedure minimally invasive for the animal, and easier to perform at sea. This preliminary trial highlights the value of interdisciplinary collaboration and the strong potential of the procedure, justifying further exploration of its application.

Keywords: Biologging, Telemetry, Surgery, Elasmobranch

\section{Background}

Tracking the movements of marine vertebrates to study their behaviour and ecology is commonly achieved using acoustic telemetry, whereby transmitters are often surgically implanted into the abdomen to avoid the drawbacks of external tag placement (shedding, irritation, fouling, etc., $[1,2])$. To place a transmitter, incisions typically need to be $\sim 5 \mathrm{~cm}$ long and cut through the dermal and muscle layers with a scalpel to access the peritoneal cavity-multiple sutures are then required to close the wound $[3,4]$. Such a procedure can be particularly challenging on large marine species, where due to logistical constraints (e.g. impracticality of removing them from the water [5]), surgery is typically performed at sea with the animal in the water alongside a vessel $[6,7]$. The challenge of open ocean surgery is to implant transmitters

*Correspondence: j12086@cam.ac.uk

2 Department of Zoology, University of Cambridge, Cambridge, UK

Full list of author information is available at the end of the article with the smallest incision, the least trauma and the shortest time to minimise any risk of morbidity or mortality to the animal [8]. Given the invasiveness of such a procedure and difficulty of achieving full aseptic technique at sea $[5,9]$, there are concerns about how internal tagging protocol on marine species may impact animal welfare [8], and it is the responsibility of researchers to ensure any procedure is as safe and efficient as possible $[5,10]$.

Translating certain advances in human medicine to animal telemetry could help reduce the invasiveness of transmitter implantation and make it easier to operate in difficult oceanic conditions. In recent years, open surgical incision of the abdominal wall has been replaced by laparoscopic surgery in many human operations [11-13]. Laparoscopy uses a trocar to pass instruments through small holes in the abdomen to perform the surgery inside ('keyhole surgery' [14]). A trocar is a tube that has a removable obturator that is used to part the muscle and fascial layers of the abdominal wall after an incision is made through the skin $[14,15]$. Trocars 
are beneficial as the incisions are much smaller (often only a few millimetres), and they are easier and faster to use than cutting through layers of tissue with a scalpel, which would also take longer to close [15]. By reducing incision length and not cutting multiple layers of muscle, atraumatic access to the abdominal cavity using trocars has been very successful in making advanced surgeries only minimally invasive, subsequently reducing trauma, surgery duration and recovery times $[16$, 17]. If a similar technique were used for tag implantation in marine species, only the skin would need to be incised and only to the diameter of the trocar, which can then atraumatically separate the muscle and access the abdominal cavity. The trocar then acts as a conduit into the coelom through which a tag can be placed quickly and easily.

Another challenge for researchers performing transmitter implantation is the subsequent closure of a $\sim 5 \mathrm{~cm}$ wound, which can be particularly difficult in open ocean. Traditionally, this has been performed using regular absorbable braided sutures $[18,19]$. In humans, the introduction of barbed suture material in surgery has made skin closure, anastomoses and reconstruction significantly easier and much quicker [20,21]. Barbed sutures possess small microscopic barbs that are laser cut into the suture and grip the tissue like a fish hook or urchin barb [22, 23]. The barbs in the tissue do not loosen and grip the tissue together without the need to tie the suture. The use of barbed sutures to close the skin incision in acoustic tagging of marine species has not previously been reported but has the potential to improve and simplify the skin closure process.

Here, we describe the translation of surgical technology and techniques from the human surgical operating room to the open ocean on marine vertebrates. Specifically, we report on the preliminary use of trocars and barbed sutures to facilitate the implantation of acoustic transmitters in large marine predators, using the bull shark Carcharhinus leucas and sicklefin lemon shark Negaprion acutidens as model species.

\section{Results and discussion}

During the present trial, a total of five sharks of two species (bull Carcharhinus leucas and sicklefin lemon shark Negaprion acutidens) were tagged using the trocar and barbed suture methods (Table 1; Fig. 1). All procedures went smoothly, and all sharks were subsequently detected moving around the array of receivers (mean liberty 449 days as of October 2018), suggesting that all recovered with no post-release mortality. Based on the authors' previous experience of using traditional means to surgically implant over 170 acoustic transmitters [7, $24,25]$, use of the trocar made the tagging procedure significantly easier and reduced the scope for error during the motion of surgery at sea.

The incision only needed to be large enough for the trocar to pass $(2 \mathrm{~cm})$ and was thereby much smaller than traditional incisions for acoustic implantation $(5 \mathrm{~cm}$; $[3,4])$. Incising only the skin also means that no cutting edges penetrate the abdominal cavity, only the blunt leading edge of the obturator that parts the muscle layers. This greatly reduces the risk of any visceral trauma that could be caused to the animal from a sharp scalpel blade entering the abdomen and makes it much easier to implant the tag with confidence quickly, especially given the movement on the boat. As in humans [16, 17], significantly smaller incisions that do not cut muscle or present scalpel blades to the viscera could greatly increase wound healing and decrease recovery time, further reducing the impact of the procedure on the animal.

In contrast to the authors previous experience of oceanic surgery $[7,24,25]$, the use of barbed sutures greatly facilitated the suturing without the need to tie them on a moving boat. Indeed, due to the smaller incision of the trocar a suture may not even be required. Nonetheless, a single suture was used out of caution and in each case closed the wound just as well and more easily than the usual $2-3$ sutures usually used for tag implantation.

The combination of easier, more reliable tag implantation and simpler wound closure techniques mean that, in addition to posing less risk to the animal, the procedure should in general be quicker to perform than traditional

Table 1 A summary of sharks tagged using the trocar and barbed suture techniques

\begin{tabular}{|c|c|c|c|c|c|c|}
\hline Species & Date & Sex & PCL & $\mathrm{FL}$ & $\mathrm{TL}$ & Liberty (days) \\
\hline Bull shark & 22/03/2017 & $F$ & 217 & 241 & 280 & 585 \\
\hline Bull shark & 25/08/2017 & $\mathrm{F}$ & 194 & 242 & 266 & 562 \\
\hline Bull shark & 30/08/2017 & $\mathrm{F}$ & 209 & 235 & 277 & 423 \\
\hline Bull shark & 02/09/2017 & $\mathrm{F}$ & 204 & 227 & 267 & 421 \\
\hline Lemon shark & 20/03/2018 & $M$ & 156 & 182 & 220 & 233 \\
\hline
\end{tabular}

Liberty is the track duration as of October 2018

$P C L$ precaudal length $(\mathrm{cm}), F L$ fork length $(\mathrm{cm}), T L$ total length $(\mathrm{cm})$ 


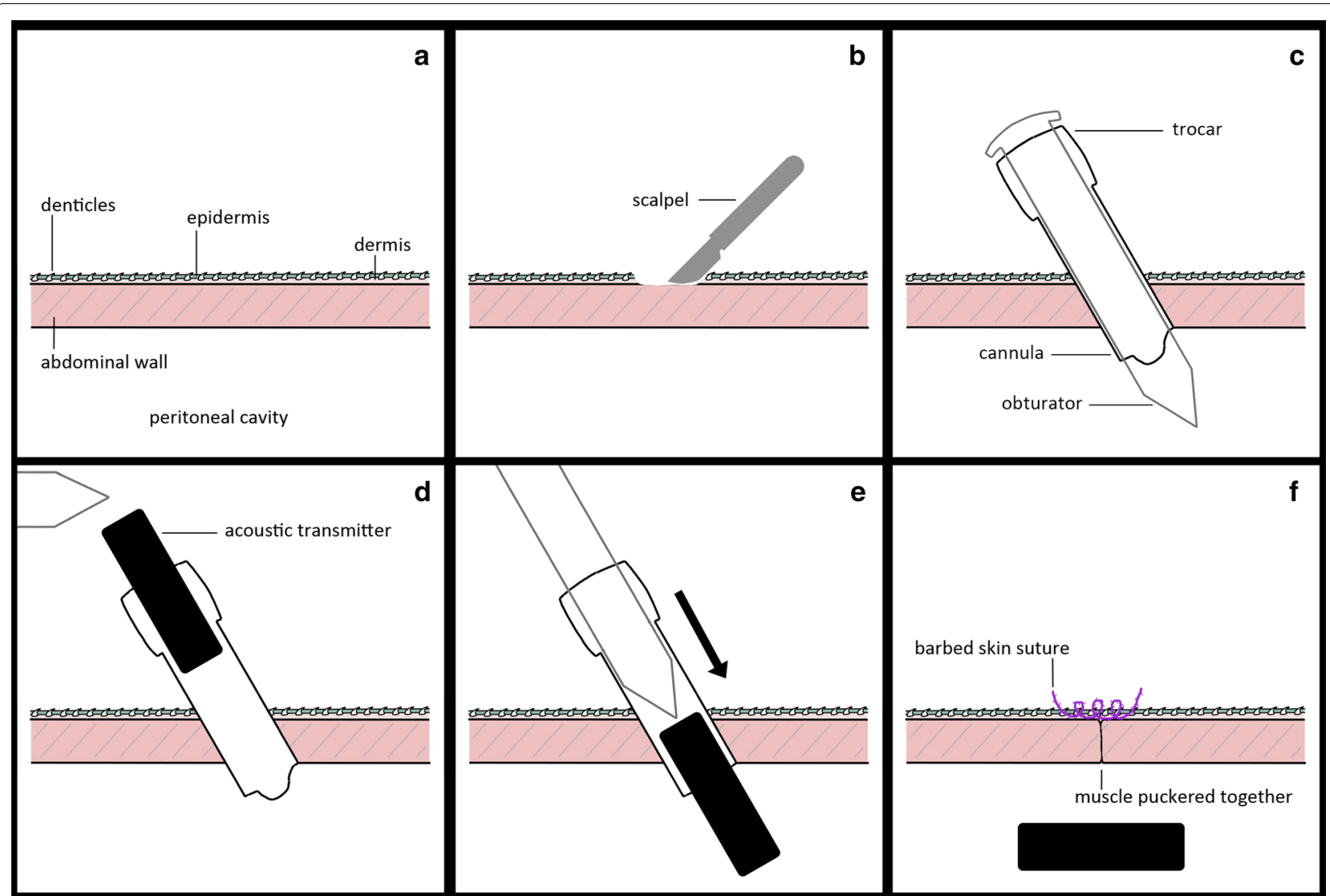

Fig. 1 A series of diagrams illustrating the use of the trocar and barbed sutures. The shark abdomen consists of denticles, epidermis, dermis and abdominal wall muscle (a), all of which must be penetrated to reach the peritoneal cavity. A scalpel was used to incise the skin down to the abdominal muscle (b). A large bore trocar was then used to twist through the muscle layers into the cavity (c). The obturator was then removed from the trocar and the acoustic transmitter inserted (d). The obturator was then reinserted to push the tag into the cavity (e). With the tag in place, a continuous barbed suture was used to close the skin, without the need for tying $(\mathbf{f})$ - the muscle pushes back together as it was not cut

tagging surgery. This will help reduce the duration of boat side tonic immobility and further minimise stress experienced by the animal [26]. While it is still crucial to have a detailed understanding of abdominal anatomy to avoid visceral damage during surgery, the simplification of the procedure could increase the accessibility of this technique to a broader audience of researchers and enhance research capacity.

There remains the issue of sterility while operating at sea, and increased consideration should be made to combat infection [5]. In addition to cleaning equipment prior to use, the application of prophylactic antibiotics could be considered as a precaution to combat infection risk [27]. Sharks regularly sustain substantial wounds through mating and predation [28-30], often healing completely and apparently without infection [31], in part attributable to the broad-spectrum antibiotic properties of numerous commensal bacteria in shark epidermal mucus [32, 33]. As such, the use of prophylactic antibiotics should be considered carefully and requires further investigation, as the benefit would have to be significant enough to warrant potentially interfering with the natural benefits of antibiotic-producing commensals. Using a trocar may also reduce the introduction of pathogens from sea water as the tag can pass through without getting wet, and the muscle is only parted, while the trocar is inserted, minimising incursion of sea water into the abdomen.

The size of the acoustic transmitters used $(16 \mathrm{~mm}$ diameter) meant that the present work was restricted to a large bore trocar, in turn limiting the size of suitable animals to $>150 \mathrm{~cm}$ in length. But smaller transmitters could be used, allowing use of smaller trocars that could further reduce trauma and be suitable for smaller species. This study is also limited by its sample size, but based on the subsequent track durations of the animals there is no evidence of increased risk of morbidity or mortality to the animal post-release, and the procedure greatly increases the ease and reduces the risk for both researcher and animal. 


\section{Conclusions}

Using trocars to access the peritoneal cavity has been very successful in humans during minimally invasive surgical abdominal procedures. We successfully transferred knowledge of trocar placement in humans to the shark model. Use of a trocar to implant a transmitter into the peritoneal cavity allowed for a smaller surgical incision and reduced abdominal trauma. In addition, use of barbed suture allowed for a rapid, tight closure of the skin without the need to tie knots. This method could have broad applications across all marine studies employing implantation of telemetry equipment. There is low risk from researchers adopting the procedure, but the benefits could be significant-this preliminary report highlights the potential of the procedure and justifies further exploration of its application.

\section{Methods}

The present study was conducted in the Amirantes Plateau, Republic of Seychelles, where there is an existing shark tracking programme [7] suitable for evaluating the surgical trocar as an alternative tag implantation method for marine species. Sharks were caught using handlines and secured in-water alongside the research vessel. Tonic immobility was induced in caught sharks to assist with tag implantation, where they were turned ventral surface upwards and entered a natural state of torpor without muscle tone or response to major stimuli [26, 34]. Tonic immobility is considered an effective anaesthetic for surgical implantation in elasmobranchs, and a valid alternative to traditional chemical anaesthetics in the field [9]. The rapid induction of, and recovery from, tonic immobility reduces animal handling time versus administering chemical anaesthesia, which is favourable under difficult oceanic conditions and when increased handling time greatly increases the risk of stress-related complications $[9,26,35]$. Given the open ocean environment of the inwater surgery, it was not possible to achieve full aseptic technique as recommended in best practice guidelines [5], but to help reduce any infection risk all instruments and tags were cleaned with ethanol and allowed to dry prior to use.

Figure 1 details the trocar tagging technique. Once in tonic immobility, an incision was made on the sharks' ventral surface, one finger breadth lateral to the midlinehere the abdominal wall is narrow, meaning the trocar has less muscle to part, while avoiding vessels that run down the midline. The incision was made using a size 22 surgical blade (Bard-Parker, Aspen Surgical, Caledonia, USA) through the skin, $\sim 2 \mathrm{~cm}$ in length. A large bore, $20 \mathrm{~mm}$ diameter, blunt stainless-steel trocar (51-20004, blueendo $\mathrm{GmbH}$ international, Geisingen, Germany) was used to part the muscle and enter the peritoneal cavity. The obturator of the trocar was then removed from the cannula. An acoustic transmitter (V16, Vemco Ltd, Bedford, Canada) of $16 \mathrm{~mm}$ diameter was placed through the cannula and pushed gently into the peritoneal cavity using the obturator. The cannula was then removed, and the incision was checked for haemostasis. The skin incision was then closed using a barbed 0-polydioxanone suture with a T9 taper needle (VLP-1001, Quill, PA, USA). The suture was placed bi-directionally across the incision for a water tight closure. The use of the barbed suture did not require tying of the knot.

Post-implantation sharks were released and subsequently tracked on an array of acoustic receivers (VR2W, Vemco Ltd, Bedford, Canada).

\section{Abbreviations}

M: male; F: female; PCL: precaudal length; FL: fork length; TL: total length.

\section{Authors' contributions}

EP and CC conceived the study. EP and JL performed the field work. EP and $J L$ wrote the manuscript. All authors read and approved the final manuscript.

\section{Author details}

${ }^{1}$ Save Our Seas Foundation Shark Research Center, 8000 North Ocean Drive, Dania Beach, FL 33004, USA. ${ }^{2}$ Department of Zoology, University of Cambridge, Cambridge, UK. ${ }^{3}$ Marine Research Facility, P.O. Box 10646, Jeddah 21443, Saudi Arabia.

\section{Acknowledgements}

All the divers, ship crews, engineers and volunteers at the D'Arros Research Centre provided invaluable assistance during fieldwork. EP thanks Professor Mahmood Shivji for his guidance and mentorship.

\section{Competing interests}

The authors declare that they have no competing interests.

\section{Availability of data and materials}

The data sets used and analysed during the current study are available from the corresponding author on request.

\section{Consent for publication \\ Not applicable.}

\section{Ethics approval and consent to participate}

The shark handling and tagging methods were performed in accordance with the approved guidelines of Nova Southeastern University, USA, and the Ministry of Environment, Energy, and Climate Change, Seychelles.

\section{Funding}

The authors wish to thank the Founder of the Save Our Seas Foundation for funding and providing all facilities for this work.

\section{Publisher's Note}

Springer Nature remains neutral with regard to jurisdictional claims in published maps and institutional affiliations.

Received: 21 November 2018 Accepted: 13 February 2019

Published online: 25 February 2019 


\section{References}

1. Cooke S, Midwood J, Thiem J, Klimley P, Lucas M, Thorstad E, et al. Track ing animals in freshwater with electronic tags: past, present and future. Anim Biotelem. 2013;1:5.

2. Donaldson M, Hinch S, Suski C, Fisk A, Heupel M, Cooke S. Making connections in aquatic ecosystems with acoustic telemetry monitoring. Front Ecol Environ. 2014:12:565-73.

3. Chapman DD, Pikitch EK, Babcock E, Shivji MS. Marine reserve design and evaluation using automated acoustic telemetry: a case-study involving coral reef-associated sharks in the Mesoamerican Caribbean. Mar Technol Soc J. 2005;39:42-55.

4. Haulsee DE, Fox DA, Breece MW, Clauss TM, Oliver MJ. Implantation and recovery of long-term archival transceivers in a migratory shark with high site fidelity. PLoS ONE. 2016;11:e0148617.

5. Mulcahy DM. Surgical implantation of transmitters into fish. ILAR J. 2003:44:295-306.

6. Lowe C, Wetherbee B, Meyer C. Using acoustic telemetry monitoring techniques to quantify movement patterns and site fidelity of sharks and giant trevally around French Frigate Shoals and Midway Atoll. Atoll Res Bull. 2006:543:281-303.

7. Lea J, Humphries N, von Brandis R, Clarke C, Sims D. Acoustic telemetry and network analysis reveal space-use of multiple reef predators and enhance MPA design. Proc R Soc Lond B Biol Sci. 2016;283:20160717.

8. Jepsen N, Koed A, Thorstad EB, Baras E. Surgical implantation of telemetry transmitters in fish: how much have we learned? Aquat Telem. 2002;483:239-48

9. Kessel ST, Hussey NE. Tonic immobility as an anaesthetic for elasmobranchs during surgical implantation procedures. Can J Fish Aquat Sci. 2015:72:1287-91.

10. Mulcahy D. Legal, ethical, and procedural bases for the use of aseptic techniques to implant electronic devices. J Fish Wildl Manag. 2013:4:211-9.

11. Neumann P, Rijcken E, Bruewer M. Current status of laparoscopic surgery for patients with Crohn's disease. Int J Colorectal Dis. 2013;28:599-610.

12. Park J, Kim K, Lee S. Laparoscopic living donor hepatectomy: a review of current status. J Hepato Biliary Pancreatic Sci. 2015;22:779-88.

13. Ganatra A, Rozet F, Sanchez-Salas R, Barret E, Galiano M, Cathelineau X, et al. The current status of laparoscopic sacrocolpopexy: a review. Eur Urol. 2009;55:1089-105

14. Soper N, Swanström L, Eubanks S, editors. Mastery of endoscopic and laparoscopic surgery. Philadelphia: Lippincott Williams \& Wilkins; 2008.

15. Ahmad G, Gent D, Henderson D, O'Flynn H, Phillips K, Watson A. Laparoscopic entry techniques. Cochrane Database Syst Rev. 2015;8:CD006583.

16. Schoonderwoerd L, Swank D. The role of optical access trocars in laparoscopic surgery. Surg Technol Int. 2005;14:61-7.

17. Bruhat M, Chapron C, Mage G, Pouly J, Canis M, Wattiez A, et al. The benefits and risks of laparoscopic surgery. Rev francaise de Gynecol et d'obstetrique. 1993:88:84-8

18. Cooke S, Graeb B, Suski C, Ostrand K. Effects of suture material on incision healing, growth and survival of juvenile largemouth bass implanted with miniature radio transmitters: case study of a novice and experienced fish surgeon. J Fish Biol. 2003;62:1366-80.
19. Deters K, Brown R, Carter K, Boyd J. Performance assessment of suture type in juvenile Chinook salmon surgically implanted with acoustic transmitters. Richland, WA: Pacific Northwest National Lab (PNNL); 2009. p. No. PNNL-18010.

20. Matarasso A, Rosen A. New and emerging uses of barbed suture technology in plastic surgery. Aesthet Surg J. 2013;33:90-5.

21. Matarasso A, Moya A. Barbed sutures in body surgery. Aesthet Surg J. 2013;33:57-71

22. Weld K, Ames C, Hruby G, Humphrey P, Landman J. Evaluation of a novel knotless self-anchoring suture material for urinary tract reconstruction. Urology. 2006;67:1133-7.

23. Ingle N, King M. Optimizing the tissue anchoring performance of barbed sutures in skin and tendon tissues. J Biomech. 2010;43:302-9.

24. Clarke C, Lea JSE, Ormond RFG. Reef-use and residency patterns of a baited population of silky sharks, Carcharhinus falciformis, in the Red Sea. Mar Freshw Res. 2011;62:668-75.

25. Lea JSE, Humphries NE, Clarke CR, Sims DW. To Madagascar and back: long-distance, return migration across open ocean by a pregnant female bull shark Carcharhinus leucas. J Fish Biol. 2015;87:1313-21.

26. Brooks EJ, Sloman KA, Liss S, Hassan-Hassanein L, Danylchuk AJ, Cooke SJ, et al. The stress physiology of extended duration tonic immobility in the juvenile lemon shark, Negaprion brevirostris (Poey 1868). J Exp Mar Bio Ecol. 2011;409:351-60.

27. Mulcahy DM. Antibiotic use during the intracoelomic implantation of electronic tags into fish. Rev Fish Biol Fish. 2011:21:83-96.

28. Stevens J. The occurrence and significance of tooth cuts on the blue shark (Prionace glauca L.) From British Waters. J Mar Biol Assoc U K. 1974;54:373-8

29. Fitzpatrick B, Meekan M, Richards A. Shark attacks on a whale shark (Rhincodon typus) at Ningaloo Reef. West Aust Bull Mar Sci. 2006:78:397-402.

30. Hoyos-Padilla M, Papastamatiou Y, O'Sullivan J, Lowe C. Observation of an attack by a cookiecutter shark (Isistius brasiliensis) on a white shark (Carcharodon carcharias). Pac Sci. 2013;67:129-34.

31. Chin A, Mourier J, Rummer JL. Blacktip reef sharks (Carcharhinus melanopterus) show high capacity for wound healing and recovery following injury. Conserv Physiol. 2015;3:cov062.

32. Ritchie KB, Schwarz M, Mueller J, Lapacek VA, Merselis D, Walsh CJ, et al. Survey of antibiotic-producing bacteria associated with the epidermal mucus layers of rays and skates. Front Microbiol. 2017:8:1050.

33. Conrad D, Gilâ-Agudelo D, Ritchie K. Antibiotic-producing bacteria associated with sharks of St. Helena and Port Royal Sound. In: Georgia undergraduate research conference; 2018.

34. Henningsen AD. Tonic immobility in 12 elasmobranchs: use as an aid in captive husbandry. Zoo Biol. 1994;13:325-32.

35. Gallagher AJ, Serafy JE, Cooke SJ, Hammerschlag N. Physiological stress response, reflex impairment, and survival of five sympatric shark species following experimental capture and release. Mar Ecol Prog Ser. 2014:496:207-18.

\footnotetext{
Ready to submit your research? Choose BMC and benefit from:

- fast, convenient online submission

- thorough peer review by experienced researchers in your field

- rapid publication on acceptance

- support for research data, including large and complex data types

- gold Open Access which fosters wider collaboration and increased citations

- maximum visibility for your research: over 100M website views per year
}

At BMC, research is always in progress.

Learn more biomedcentral.com/submissions 